\title{
Using SWAT and Fuzzy TOPSIS to Assess the Impact of Climate Change in the Headwaters of the Segura River Basin (SE Spain)
}

\author{
Javier Senent-Aparicio *, Julio Pérez-Sánchez, Jesús Carrillo-García and Jesús Soto \\ Department of Civil Engineering, Catholic University of San Antonio, Campus de los Jerónimos s/n, \\ 30107 Murcia, Spain; jperez058@ucam.edu (J.P.-S.); jacarrillo2@alu.ucam.edu (J.C.-G.); jsoto@ucam.edu (J.S.) \\ * Correspondence: jsenent@ucam.edu; Tel.: +34-968-278-818 \\ Academic Editors: Karim Abbaspour, Raghavan Srinivasan, Saeid Ashraf Vaghefi, Monireh Faramarzi and \\ Lei Chen \\ Received: 9 January 2017; Accepted: 17 February 2017; Published: 22 February 2017
}

\begin{abstract}
The Segura River Basin is one of the most water-stressed basins in Mediterranean Europe. If we add to the actual situation that most climate change projections forecast important decreases in water resource availability in the Mediterranean region, the situation will become totally unsustainable. This study assessed the impact of climate change in the headwaters of the Segura River Basin using the Soil and Water Assessment Tool (SWAT) with bias-corrected precipitation and temperature data from two Regional Climate Models (RCMs) for the medium term (2041-2070) and the long term (2071-2100) under two emission scenarios (RCP4.5 and RCP8.5). Bias correction was performed using the distribution mapping approach. The fuzzy TOPSIS technique was applied to rank a set of nine GCM-RCM combinations, choosing the climate models with a higher relative closeness. The study results show that the SWAT performed satisfactorily for both calibration $(\mathrm{NSE}=0.80)$ and validation $(\mathrm{NSE}=0.77)$ periods. Comparing the long-term and baseline $(1971-2000)$ periods, precipitation showed a negative trend between $6 \%$ and $32 \%$, whereas projected annual mean temperatures demonstrated an estimated increase of $1.5-3.3^{\circ} \mathrm{C}$. Water resources were estimated to experience a decrease of $2 \%-54 \%$. These findings provide local water management authorities with very useful information in the face of climate change.
\end{abstract}

Keywords: water resources; SWAT model; climate change; Segura Basin; fuzzy TOPSIS

\section{Introduction}

Climate change as a result of increased greenhouse gas emissions leads to changes in hydrologic conditions and results in various impacts on the availability of global water resources [1]. Spain is one of the countries most vulnerable to the impacts of climate change in Europe due to the high spatial and temporal irregularity of water resources and socio-economic characteristics [2]. In addition, future climate tendencies show an increment in the temperature and a significant reduction in total annual rainfall [3]. When these impacts occur in regions that already present low water resource availability and frequent droughts, these impacts can be exacerbated. The Segura River Basin (SRB) is situated in SE Spain and is one of the most water-stressed basins in Mediterranean Europe [4].

In global terms, the total water demand for consumption is $1800 \mathrm{hm}^{3} /$ year, where $86 \%$ corresponds to agricultural use and 10\% to urban uses. Against this demand data, annual natural water availability is, on average, around $800 \mathrm{hm}^{3} /$ year [5]. This deficit is partly covered by water from the Tagus-Segura water transfer and the use of unconventional water resources like treated wastewater and desalinated water, but these resources are not enough and the SRB is still suffering aquifer overexploitation [6]. The headwaters of the Segura River Basin (HWSRB) need to be studied 
thoroughly, as they are the most important sites for water resource generation in the basin [7]. The HWSRB have an important relevance in SRB water resources, since they comprise $9 \%$ of the water resource contribution, in spite of the fact that they covers only $1.2 \%$ of the area of the total watershed.

The SWAT has been successfully and widely used all over the world for different purposes, including the evaluation of climate change impacts on water resources [8]. However, SWAT applications assessing the water resources of Spain under changing climate conditions are scarce in scientific literature. Such studies have mostly been conducted in the north of the country, where there is an absence of water scarcity [9-14]. In the case of Spanish Mediterranean catchments, this model has rarely been used [15].

The Technique for Order Preference by Similarity to an Ideal Solution (TOPSIS) is one of the most used techniques for solving Multi-Criteria Decision Analysis (MCDA) problems and was first developed by Hwang and Yoon [16]. In the classic formulation of the TOPSIS method, personal judgements are represented with crisp values. However, crisp data are inadequate to model real-life decision problems under many conditions. That is why the fuzzy TOPSIS method was proposed, whereby the weights of criteria and ratings of alternatives are evaluated by linguistic variables represented by fuzzy numbers to deal with the deficiency in the classic TOPSIS. The fuzzy TOPSIS method has been widely applied in many fields; for example, energy [17], environment [18], industrial processes [19], and climate change [20]. However, to the best of our knowledge, the only precedent in the combined use of the SWAT model and the fuzzy TOPSIS method is found in Won et al. [21], wherein the authors assessed the water use vulnerability in 12 basins of South Korea, using SWAT to simulate hydrological components and fuzzy TOPSIS to rank the water use vulnerability in those basins.

The aim of the present study was to evaluate the climate change effect on the water resources of the HWSRB. The specific objectives of this study included: (1) to reduce the uncertainty in climate change projections by applying the fuzzy TOPSIS technique to rank climate models and (2) to explore the water resource response to future climate projections for the HWSRB. To achieve these objectives, we set up a hydrological model, using SWAT for the HWSRB. After calibration and validation of the model, nine different climate models were downloaded from the EURO-CORDEX initiative [22] and the fuzzy TOPSIS technique was applied to select which historical runs had the best fit with the observed climate data during a baseline period (1971-2000). Once those climate models were ranked, some of them were used to evaluate climate change in the study area for the medium term (2041-2070) and long term (2071-2100) using two different representative concentration pathways (RCP4.5 and RCP8.5). The results obtained in this study provide local water management authorities with very useful information for the proper utilisation and management of water resources under climate change conditions in this vulnerable region.

\section{Description of the Study Area}

The HWSRB is located in the southeastern region of Spain and covers an area of about $235 \mathrm{~km}^{2}$. The basin is characterised by steep terrain, and the elevation ranges between 898 and $1912 \mathrm{~m}$, as is shown in Figure 1. The drainage network is formed by two main rivers, the Segura River and its tributary, the Madera River. The whole basin drains into the Anchuricas Reservoir. The mean discharge at the reservoir is $1.6 \mathrm{~m}^{3} / \mathrm{s}$. This reservoir was constructed in 1957; it has a capacity of $6 \mathrm{hm}^{3}$, and the key purpose of the reservoir is to generate electricity. The study area is located mostly on permeable outcrops, limestone, and dolomite of the Upper Cretaceous. Land use in the watershed is highly forested; $61 \%$ of the surface is occupied by forests and $19 \%$ by Mediterranean shrubland vegetation. The rest of the land use is mainly for range purposes. The predominant soil type is rendzic leptosol, with variable depth always less than $50 \mathrm{~cm}$, good drainage, and abundant stoniness [23].

The climate is typical Mediterranean with clear seasonality, rainy springs and autumns, and dry summers. According to data from 1971 to 2000, the mean annual precipitation ranged from 511 to $1300 \mathrm{~mm}$, with an average value of $878 \mathrm{~mm}$ for the HWSRB, and the average annual temperature was $12.4^{\circ} \mathrm{C}$. 


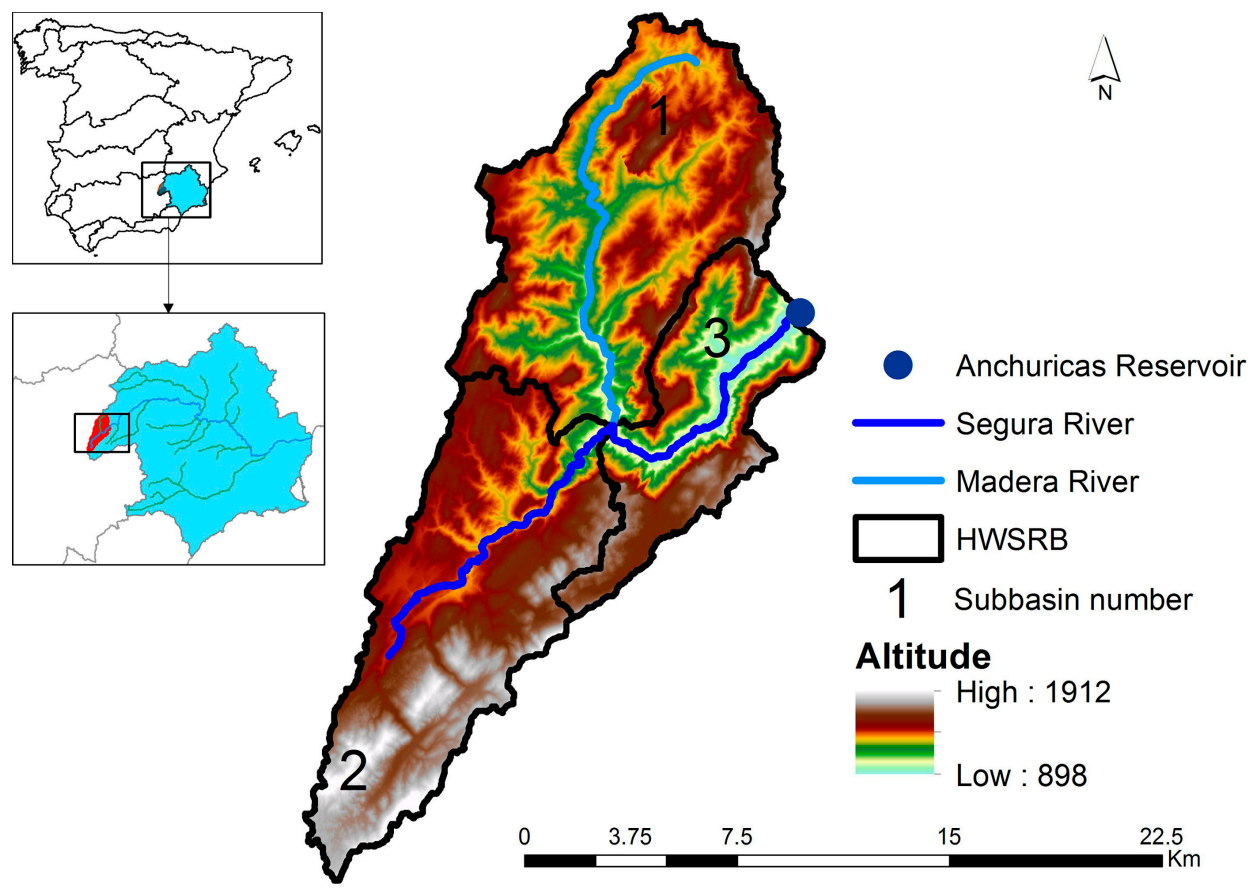

Figure 1. Location of the headwaters of the Segura River Basin (HWSRB).

\section{Methodology}

In order to evaluate the future impacts of climate change on water resources, the hydrological cycle was simulated in the headwaters of the SRB under different climate change scenarios. This process included three main steps: (1) setting up the hydrological model with observed stream flow and climate data; (2) selecting climate projections based on the fuzzy TOPSIS technique; and (3) incorporating climate scenarios into the hydrological model to evaluate the impact of the climate change in the headwaters of the SRB in the medium term (2041-2070) and long term (2071-2100).

\subsection{SWAT Model}

The SWAT [24] is a hydrological watershed model to evaluate the land practice water, sediment transport, and agricultural chemical yields in complex watersheds where soils, land use, or management can widely change.

The SWAT is a semi-distributed and physically based model. The balance equation used is

$$
\mathrm{SW}_{\mathrm{t}}=\mathrm{SW}_{\mathrm{O}}+\sum\left(\mathrm{R}_{\text {day }}-\mathrm{Q}_{\text {surf }}-\mathrm{E}_{\mathrm{a}}-\mathrm{W}_{\text {seep }}-\mathrm{Q}_{\mathrm{gw}}\right)
$$

where $S W_{t}$ is the final water soil content, $S W_{O}$ is the initial water soil content, $R_{\text {day }}$ is the precipitation, $Q_{\text {surf }}$ is the surface runoff, $E_{a}$ is the evapotranspiration, $W_{\text {seep }}$ is the percolation, and $\mathrm{Q}_{\mathrm{gw}}$ is the amount of baseflow (all in $\mathrm{mm}$ ).

The basin is divided into sub-basins and those, in turn, are divided into hydrologic response units (HRUs). HRUs are defined by homogeneous regions with the same slope, soil, and land use. Each HRU generates an amount of runoff that is routed to calculate the total runoff. In order to calculate HRUs, the slope was divided into three classes $(0 \%-8 \%, 8 \%-30 \%$ and $>30 \%)$ and a threshold level of $10 \%$ was established to facilitate model processing and eliminate minor soils, slopes, and land uses for each subbasin. 


\subsubsection{Input Data for Hydrological Modelling}

As for the data used to carry out the hydrological modelling, catchments were defined based on the digital elevation model (DEM), available on the website of the National Center for Geographic Information [25], with an accuracy of $25 \mathrm{~m} \times 25 \mathrm{~m}$. Meteorological data were obtained from the high-resolution (approximately $12 \mathrm{~km} \times 12 \mathrm{~km}$ ) gridded data set called SPAIN02. Detailed documentation of the development and analysis of the SPAIN02 data set can be found in Herrera et al. [26]. In this study, potential evapotranspiration was simulated using the Hargreaves method [27] due to the fact that it only requires minimum and maximum temperatures. Oudin et al. [28] checked that water balance models using parsimonious temperature-based methods perform similarly well compared to more data-demanding methods. The discharge data at the catchment outlet were available on the Hydrographical Study Centre website [29].

In addition to DEM, the Geographic Information Systems (GIS) input data required to build the SWAT model setup included a land cover map and a soil map. Land cover data were derived from reclassified Corine Land Cover 2006 [30] $(1: 50,000)$. The soil data for the HWSRB were obtained from the Harmonized World Soil Database (HWSD), assembled by the Food and Agriculture Organization of the United Nations (FAO). This database provides data for 16,000 map units containing two different soil layers (0-30 and 30-100 cm deep) [31].

\subsubsection{Calibration and Validation of the SWAT Model}

Sensitivity analysis was conducted to identify the most influential parameters for streamflow simulation, which were adjusted during calibration. Automatic calibration with the Sequential Uncertainty Fitting programme algorithm (SUFI-2) [32] was run with the sensible parameters and with other relevants in baseflow, groundwater, and runoff to improve the fit. SUFI-2 is a stochastic calibration that provides some relation between calibration and the uncertainty associated with ignorance about natural systems and all other sources, such as driving variables, conceptual model, parameters, and measured data. Detailed documentation of the SUFI-2 algorithm can be found in Abbaspour et al. [33].

The SWAT model was calibrated using monthly streamflow data for a period of thirteen years (1988-2000). Calibration is the process when observed and generated values are fitted as much as possible, searching for the best optimisation of an objective function; the Nash-Sutcliffe efficiency, in this case [34]. After calibration, the model was validated using the monthly discharge data of twelve years (1976-1987). Five years (1971-1975) were used to warm up the model in order to mitigate the effects of the initial conditions on the model output. With the best iteration parameters, the model performance was tested in a validation period and evaluated, as is shown in Table 1.

Table 1. Evaluation criteria for model performance [34].

\begin{tabular}{cccc}
\hline Performance Rating & NSE & RSR & PBIAS (\%) \\
\hline Very good & $0.75<$ NSE $\leq 1.00$ & $0.00 \leq$ RSR $\leq 0.50$ & PBIAS $< \pm 10$ \\
Good & $0.65<$ NSE $\leq 0.75$ & $0.50<$ RSR $\leq 0.60$ & $\pm 10 \leq$ PBIAS $< \pm 15$ \\
Satisfactory & $0.50<$ NSE $\leq 0.65$ & $0.60<$ RSR $\leq 0.70$ & $\pm 15 \leq$ PBIAS $< \pm 25$ \\
Unsatisfactory & NSE $\leq 0.50$ & RSR $>0.70$ & PBIAS $\geq \pm 25$ \\
\hline
\end{tabular}

Moriasi et al. [35] recommended the Nash-Sutcliffe efficiency (NSE), root mean square error to the standard deviation ratio (RSR), and percent bias (PBIAS) as evaluation criteria for model performance.

\subsection{Climate Scenarios and Statistical Bias Correction Method}

The climate simulations used in this study consisted of 9 combinations of General Circulation Models and Regional climate models (GCM-RCM) from the EURO-CORDEX initiative [22] with a grid spacing of about $12.5 \mathrm{~km}\left(0.11^{\circ}\right.$ on a rotated grid). The EURO-CORDEX is an international climate downscaling initiative that aims to provide high-resolution climate scenarios for Europe [36]. The 
simulations have been produced assuming concentration pathways RCP4.5 and RCP8.5, described in van Vuuren et al. [37], and are listed in Table 2. For this study, 30 years of data from historical simulation runs (1971-2000) were used as the baseline period. The future climate is represented with two 30-year periods from the scenario simulation runs; medium term (2041-2070) and long term (2071-2100).

Table 2. Overview of the Regional Climate Models (RCMs) considered.

\begin{tabular}{ccc}
\hline \multicolumn{1}{c}{ Institution } & RCM & Driving Model \\
\hline Climate Limited-Area Modelling Community (CLMcom) & CCLM4-8-17 & CNRM-CM5 \\
Climate Limited-Area Modelling Community (CLMcom) & CCLM4-8-17 & MPI-ESM-LR \\
Danish Meteorological Institute (DMI) & HIRHAM5 & EC-EARTH \\
Climate Service Centre in Hamburg, Germany (CSC) & REMO2009 & MPI-ESM-LR \\
Royal Netherlands Meteorological Institute (KNMI) & RACMO22E & EC-EARTH \\
Swedish Meteorological and Hydrological Institute (SMHI) & RCA4 & CNRM-CM5 \\
Swedish Meteorological and Hydrological Institute (SMHI) & RCA4 & EC-EARTH \\
Swedish Meteorological and Hydrological Institute (SMHI) & RCA4 & MPI-ESM-LR \\
Institut Pierre-Simon Laplace (IPSL-INERIS) & WRF331F & IPSL-CM5A-MR \\
\hline
\end{tabular}

It is well known that climate model output data contain systematic errors and cannot be used directly in hydrological simulations [38]. That is why a bias correction technique was also applied to the downscaled data to increase the accuracy of the results. In this study, the bias correction technique based on distribution mapping of precipitation and temperature was applied. The idea of distribution mapping is to correct the distribution function of climate model values to agree with the observed distribution function. In 2012, Teutschbein and Seibert [39] evaluated different methods for bias correction of regional climate model simulations for hydrological climate change impact studies, and they obtained very good results applying this technique. In order to extract and bias correct data obtained from the climate models, the CMhyd tool was used [40].

\subsection{Fuzzy TOPSIS}

Fuzzy TOPSIS is based on the distance of each indicator for each regional climate model from the ideal solution. The steps followed in the application of this technique first include the determination of the fuzzy decision matrix, taking into account the number of climate models used and the indicators evaluated. After that, in order to homogenise the evaluation supplied for all the criteria, their values must be linearly normalised. Finally, the proximity coefficients $\left(D_{i}^{+}, D_{i}^{-}\right)$for each alternative are calculated in accordance with ideal and anti-ideal values selected for each indicator. This technique is designed to minimise the distance of a data object from the positive ideal solution $\left(D_{i}^{+}\right)$and maximise the distance from the negative ideal solution $\left(D_{i}^{-}\right)$[14]. The closeness coefficient $\left(C_{i}\right)$ of each alternative is calculated as:

$$
C_{i}=\frac{D_{i}^{-}}{\left(D_{i}^{-}+D_{i}^{+}\right)}
$$

To establish the ranking of climate models, it is sufficient to sort them according to the decreasing values of their closeness coefficient. A clear example of a fuzzy approach to ranking climate models can be found in Raju and Kumar (2015) [20]. The climatic variables used were precipitation, minimum temperature, and maximum temperature. The correlation coefficient (CC), normalised root mean square deviation (NRMSD), and skill score (SS) [41] were used as performance indicators. Equal weights were considered for each criterion, and ideal and anti-ideal values for all the indicators were chosen as $(1,1,1)$ and $(0,0,0)$. 


\section{Results and Discussion}

\subsection{Calibration and Validation}

A global sensitivity analysis found the following sensible parameters (Table 3): SOL_AWC, LAT_TTIME, SOL_BD, GW_REVAP, ALPHA_BF, RCHRG_DP, SOL_K, FFCB, OV_N, and GWQMN. The presence of several of these parameters showed the great importance of groundwater (ALPHA_BF, RCHRG_DP, GWQMN, and GW_REVAP) and lateral flow (LAT_TTIME) in this area, as is described in Conan et al. [42] and Galván et al. [43], where shallow aquifers have a relevant role. Some soil properties influence the opposition to the groundwater, and this justifies its presence as a sensible parameter, like SOL_AWC, SOL_K, and SOL_BD, usually listed in other studies [44].

Table 3. Range and final parameter values after calibration.

\begin{tabular}{clcc}
\hline Parameter & \multicolumn{1}{c}{ Description } & Value Range & Adjusted Value \\
\hline SOL_AWC & Available water capacity of the soil layer $(\mathrm{mm} / \mathrm{mm})$ & $(0,1)$ & 0.3 \\
LAT_TTIME & Lateral flow travel time $($ days $)$ & $(0,180)$ & 174.6 \\
SOL_BD & Moist bulk density $\left(\mathrm{Mg} / \mathrm{m}^{3}\right)$ & $(0.9,2.5)$ & 1.01 \\
GW_REVAP & Groundwater "revap" coefficient & $(0.02,0.2)$ & 0.17 \\
ALPHA_BF & Baseflow alpha factor $\left(\right.$ days $\left.{ }^{-1}\right)$ & $(0,1)$ & 0.72 \\
RCHRG_DP & Deep aquifer percolation fraction & $(0,1)$ & 0.85 \\
SOL_K & Saturated hydraulic conductivity (mm/h) & $(0,2000)$ & 14.5 \\
FFCB & Initial soil water storage expressed as a fraction of field & $(0,1)$ & 0.69 \\
OV_N & capacity water content & $(0.01,30)$ & 21.92 \\
GWQMN & Manning's "n" value for overland flow & $(0,5000)$ & 2459 \\
CN2 & return flow to occur (mm) & & $+2.40 \%$ \\
ESCO & SCS runoff curve number & $(0,1)$ & 0.56 \\
\hline
\end{tabular}

In addition to these parameters, $\mathrm{CN} 2$ was considered due to its correlation with runoff production, affecting baseflow as well. In addition, in a Mediterranean area where evapotranspiration has high relevance, ESCO was added because of its function in driving the extraction of the evaporative demand from lower soil layers $[45,46]$.

As shown in Table 3, calibration with the SUFI-2 algorithm provided the best fitted values for the parameters. The best iteration was a very good performance based on performance criteria [35], with 0.80 NSE, $1.22 \%$ PBIAS, and 0.45 RSR.

The calibrated parameters were similar to previous references in areas with similar Mediterranean, warm, or semi-arid climatic or vegetation characteristics. The GW_REVAP value is close to the upper limit of the range due to the presence of forests in the area, as occurs with OV_N [47]; this allows the transfer of water to the root zone and increases evapotranspiration [46], which affects the baseflow and points out the importance of evapotranspiration in the Mediterranean balance. ALPHA_BF has a value that set aquifers as a medium-high velocity response to recharge [46]. The FFCB value is similar to others demonstrated in other Mediterranean watersheds [48].

Validation was required after calibration. The model was run for the 1971-1987 period, including five years for a warm-up period and, as in calibration, comparing monthly streamflow observed values with the simulated values. The model performance in this step was still accurate, with statistics described as good or very good, as shown in Table 4. Only PBIAS was worse than in the calibration period.

Figure 2 shows an accurate global model performance comparing the simulated and observed values; although the calibration period was drier than the validation and the streamflow had maximum peaks in the validation period that the SWAT overestimated, this is not an unusual issue when a model is implemented [7,43]. 
Table 4. Calibration and validation period performance.

\begin{tabular}{cccccc}
\hline & Calibration & & \multicolumn{3}{c}{ Validation } \\
\hline NSE & PBIAS (\%) & RSR & NSE & PBIAS (\%) & RSR \\
\hline 0.80 & +1.22 & 0.45 & 0.77 & -12.64 & 0.48 \\
Very good & Very good & Very good & Very good & Good & Very good \\
\hline
\end{tabular}

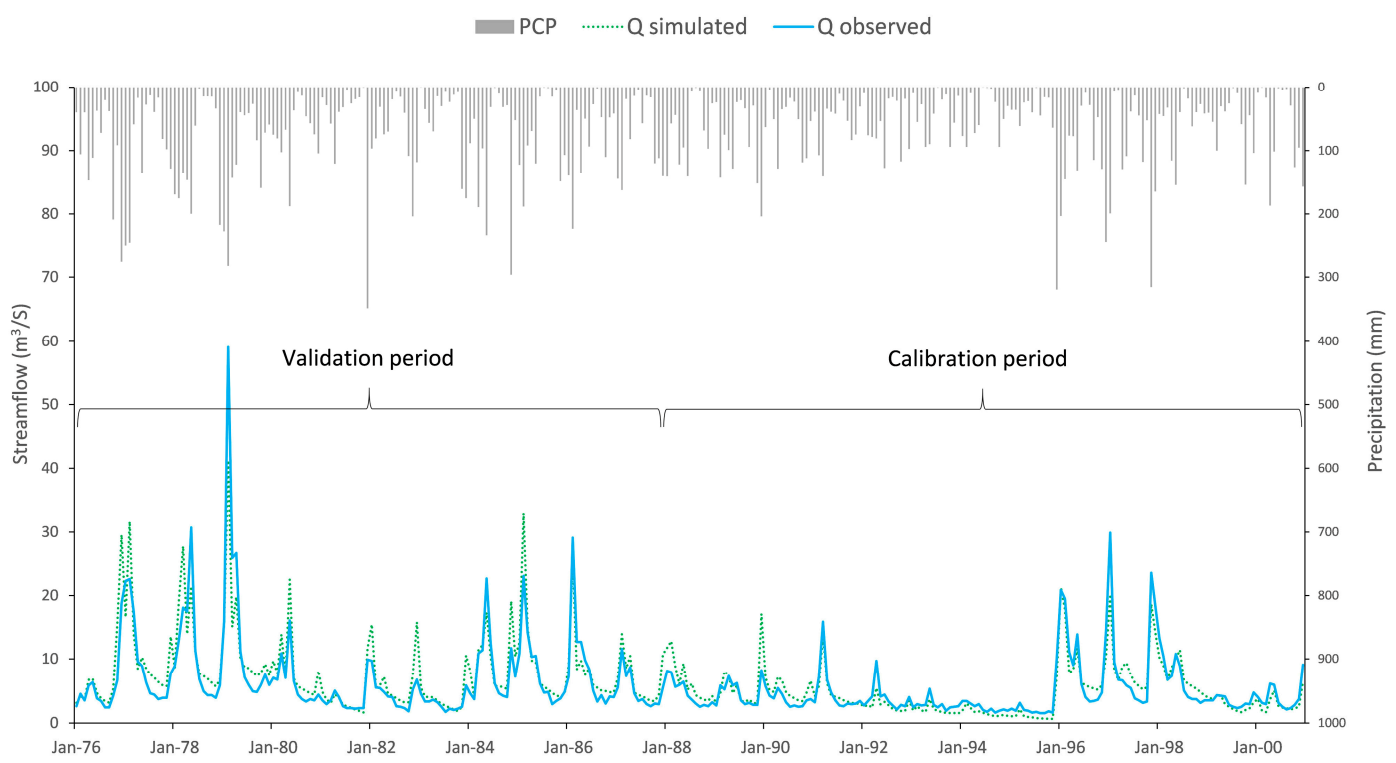

Figure 2. Soil and Water Assessment Tool (SWAT) model calibration and validation. Validation (1976-1987) and calibration (1988-2000).

\subsection{Selection of RCMs Using TOPSIS}

As shown in Table 5, data set grids relating to the period 1971-2000 obtained from SPAIN02 [26] were compared with historical runs obtained from each of the 9 RCMs to assess the CC, NRMSD, and SS under a fuzzy approach. Table 6 presents $D_{i}^{+}, D_{i}^{-}, C_{i}$, and a ranking pattern for every regional climate model used. The top three positions are occupied by RCA4_CNRM-CM5, RCA4_EC-EARTH, and HIRHAM5_EC-EARTH, with the relative closeness of 0.6216, 0.6213, and 0.4928. On the contrary, the seventh, eighth, and ninth positions are occupied by CCLM4-8-17_MPI-ESM-LR, WRF331F_IPSL-CM5A-MR, and REMO2009_MPI-ESM-LR, with the relative closeness of 0.1953, 0.1952, and 0.0951. These results suggest that RCA4_CNRM-CM5 and RCA4_EC-EARTH are suitable as input data for the SWAT modelling application in the case study.

Table 5. Normalised performance indicators obtained.

\begin{tabular}{ccccccccccc}
\hline \multirow{2}{*}{ Model } & \multicolumn{4}{c}{ CC } & \multicolumn{4}{c}{ NRMSD } & \multicolumn{3}{c}{ SS } \\
\cline { 2 - 10 } & $p_{i j}$ & $q_{i j}$ & $r_{i j}$ & $p_{i j}$ & $q_{i j}$ & $r_{i j}$ & $p_{i j}$ & $q_{i j}$ & $r_{i j}$ \\
\hline CCLM4-8-17_CNRM-CM5 & 0.5268 & 0.0000 & 0.0000 & 0.0000 & 0.9721 & 0.7978 & 0.0000 & 0.9630 & 0.7954 \\
CCLM4-8-17_MPI-ESM-LR & 0.0713 & 0.0588 & 0.9288 & 0.0766 & 0.0000 & 0.0000 & 0.0764 & 0.0000 & 0.0000 \\
HIRHAM5_EC-EARTH & 0.9960 & 0.0000 & 0.0000 & 0.9401 & 0.7408 & 0.0000 & 0.9389 & 0.7338 & 0.0000 \\
REMO2009_MPI-ESM-LR & 0.0000 & 0.3726 & 0.0000 & 0.0000 & 0.0000 & 0.1681 & 0.0000 & 0.0000 & 0.1692 \\
RACMO22E_EC-EARTH & 0.0000 & 0.8852 & 0.3098 & 0.0700 & 0.9579 & 0.0000 & 0.0699 & 0.9489 & 0.0000 \\
RCA4_CNRM-CM5 & 0.0000 & 0.9725 & 0.0000 & 0.8774 & 0.8199 & 0.8003 & 0.8785 & 0.8483 & 0.8059 \\
RCA4_EC-EARTH & 0.8780 & 0.0386 & 0.7276 & 0.4320 & 0.7606 & 0.9630 & 0.4314 & 0.7892 & 0.9698 \\
RCA4_MPI_ESM_LR & 0.5958 & 0.0344 & 0.6874 & 0.0000 & 0.2168 & 0.0000 & 0.0000 & 0.2850 & 0.0000 \\
WRF331F_IPSL-CM5A-MR & 0.0713 & 0.0588 & 0.9288 & 0.0766 & 0.0000 & 0.0000 & 0.0764 & 0.0000 & 0.0000 \\
\hline
\end{tabular}


Table 6. Ranking pattern of global climate models.

\begin{tabular}{ccccc}
\hline Model & $\boldsymbol{D}_{\boldsymbol{i}}^{+}$ & $\boldsymbol{D}_{\boldsymbol{i}}^{-}$ & $\boldsymbol{C}_{\boldsymbol{i}}$ & Rank \\
\hline CCLM4-8-17_CNRM-CM5 & 2.0399 & 1.7508 & 0.4619 & 4 \\
CCLM4-8-17_MPI-ESM-LR & 2.7382 & 0.6640 & 0.1953 & 7 \\
HIRHAM5_EC-EARTH & 2.0125 & 1.9551 & 0.4928 & 3 \\
REMO2009_MPI-ESM-LR & 2.8383 & 0.2982 & 0.0951 & 9 \\
RACMO22E_EC-EARTH & 2.3078 & 1.5022 & 0.3943 & 5 \\
RCA4_CNRM-CM5 & 1.1980 & 1.9677 & 0.6216 & 1 \\
RCA4_EC-EARTH & 1.3145 & 2.1562 & 0.6213 & 2 \\
RCA4_MPI_ESM_LR & 2.4879 & 0.8413 & 0.2527 & 6 \\
WRF331F_IPSL-CM5A-MR & 2.7382 & 0.6640 & 0.1952 & 8 \\
\hline
\end{tabular}

\subsection{Water Resource Response to Climate Change}

\subsubsection{Changes in Projected Precipitation and Temperature}

The mean annual projected precipitation and temperature are displayed in Table 7. Similar patterns are observed, with a general reduction in precipitation and a general increase in temperature. Expected changes in precipitation under RCP4.5 are totally different depending on the model analysed. While RCA4_EC-EARTH projects a slight increase in precipitation, RCA4_CNRM-CM5 projects a reduction that ranges between $13 \%$ and $19 \%$. This significant variability was also found in the climate projections published by the Spanish agency of meteorology [49]. Under the RCP8.5 scenario, both models show a negative trend in precipitation that ranges between $6 \%$ and $17 \%$ in the medium term and $32 \%$ in the long term. With regards to projected temperature compared to the baseline period, the mean annual temperature suggests a significant and steady increase across the HWSRB in both scenarios. The temperature increase across the HWSRB will range between 0.9 and $1.3^{\circ} \mathrm{C}$ in the medium term and 1.3 and $1.8^{\circ} \mathrm{C}$ in the long term in the RCP4.5 scenario and between 1.5 and $2.1{ }^{\circ} \mathrm{C}$ in the medium term and 2.7 and $3.3{ }^{\circ} \mathrm{C}$ in the long term in the RCP8.5 scenario. As for temperature, there were no exceptions; all models showed a higher increase in temperature in the long term compared to the medium term. These results are consistent with other studies in Spanish Mediterranean areas $[15,50]$.

As shown in Figure 3, the temperature increase in winter and autumn is lower than the increase in warmer months, increasing the intra-annual difference of the temperature. The lowest increase in temperature occurs in winter in the medium term in $\mathrm{RCP} 4.5\left(0.5\right.$ to $\left.1.1^{\circ} \mathrm{C}\right)$, while the largest increases occur during summer in the long term in RCP8.5 (2.9 to $\left.3.8^{\circ} \mathrm{C}\right)$. These results are consistent with other studies in small Mediterranean basins [15,50].

Table 7. Precipitation $(\mathrm{mm})$ and temperature $\left({ }^{\circ} \mathrm{C}\right)$ means with their variations.

\begin{tabular}{clcccccc}
\hline \multirow{2}{*}{ Scenario } & \multirow{2}{*}{ Model } & \multicolumn{3}{c}{ Mean Annual Precipitation } & \multicolumn{2}{c}{ Mean Annual Temperature } \\
\cline { 3 - 8 } & & $\mathbf{1 9 7 1 - 2 0 0 0}$ & $\mathbf{2 0 4 1 - 2 0 7 0}$ & $\mathbf{2 0 7 1 - 2 1 0 0}$ & $\mathbf{1 9 7 1 - 2 0 0 0}$ & $\mathbf{2 0 4 1 - 2 0 7 0}$ & $\mathbf{2 0 7 1 - 2 1 0 0}$ \\
\hline \multirow{2}{*}{ RCP4.5 } & RCA4_EC-EARTH & 862 & $885(+3 \%)$ & $871(+1 \%)$ & 12.4 & $13.7(+1.3)$ & $14.2(+1.8)$ \\
& RCA4_CNRM-CM5 & 906 & $732(-19 \%)$ & $788(-13 \%)$ & 12.4 & $13.3(+0.9)$ & $13.7(+1.3)$ \\
RCP8.5 5 & RCA4_EC-EARTH & 862 & $811(-6 \%)$ & $615(-32 \%)$ & 12.4 & $14.5(+2.1)$ & $15.7(+3.3)$ \\
& RCA4_CNRM-CM5 & 906 & $756(-17 \%)$ & $615(-32 \%)$ & 12.4 & $13.9(+1.5)$ & $15.1(+2.7)$ \\
& Observed & 877 & & & 12.4 & & \\
\hline
\end{tabular}

With respect to seasonal precipitation change (Figure 4), both models agreed on projecting a decrease in the precipitation for winter, spring, and autumn, while the precipitation will not suffer significant variations in summer. 

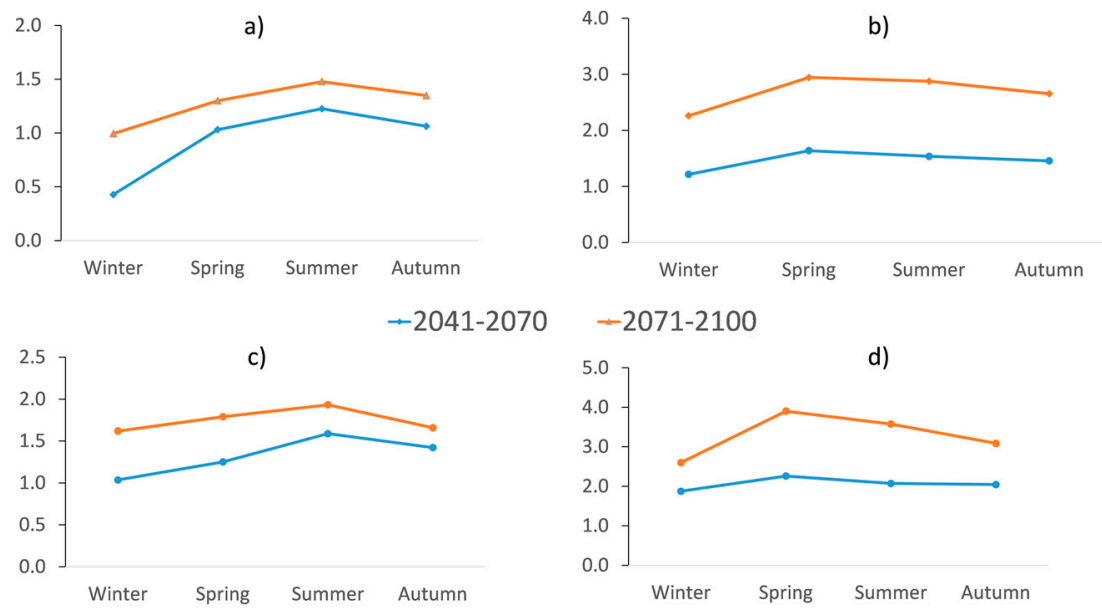

Figure 3. Seasonal temperature change $\left({ }^{\circ} \mathrm{C}\right)$ in (a) RCA4_CNRM-CM5 (RCP4.5); (b) RCA4_CNRM-CM5 (RCP8.5); (c) RCA4_EC-EARTH (RCP4.5); and (d) RCA4_EC-EARTH (RCP8.5).
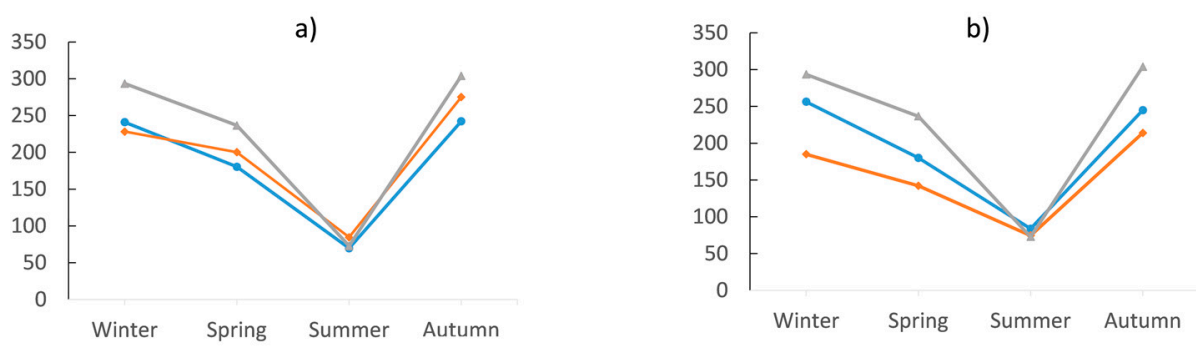

$-2041-2070-2071-2100-$ Historical
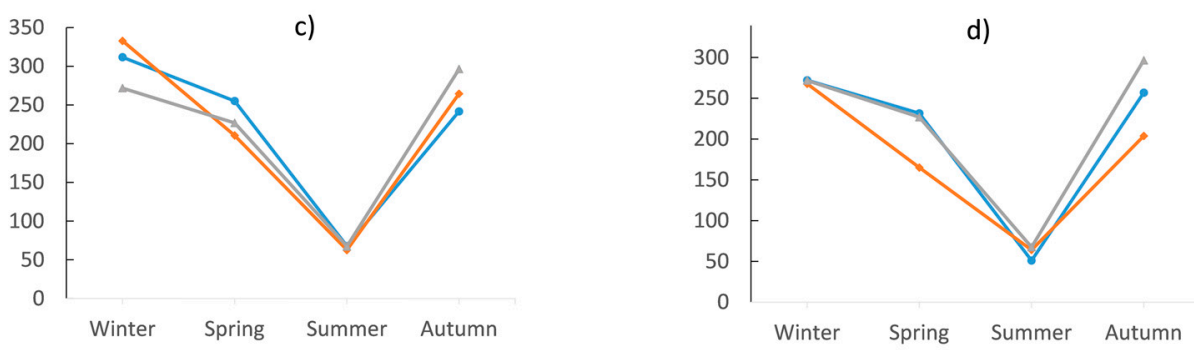

Figure 4. Seasonal precipitation change (mm) in (a) RCA4_CNRM-CM5 (RCP4.5); (b) RCA4_CNRM-CM5 (RCP8.5); (c) RCA4_EC-EARTH (RCP4.5); and (d) RCA4_EC-EARTH (RCP8.5).

\subsubsection{Annual Streamflow Change}

Under the RCP4.5 emissions scenario, the variability in the projected streamflow is very high, ranging from $+4 \%$ to $-35 \%$ in the medium term and projecting in the long term an important decrease that is expected to range between $2 \%$ and $23 \%$ (Figure 5). The possibility of a slight increment in the streamflow, as can be seen for the RCA4_EC-EARTH model, agrees with estimated projections by the Spanish government for the SRB [51], as does the prediction of a higher streamflow reduction in the medium term compared with the long term. These results can also be compared to those obtained by Estrela et al. [3], who also projected a reduction in mean annual runoff for the SRB between $21 \%$ and $33 \%$. Overall, the increase in temperature and the projected decrease in precipitation will result in increased evapotranspiration, which will interact to reduce streamflow significantly [52]. Comparing precipitation and streamflow results, it can be seen that, due to higher actual evapotranspiration, the decreases obtained in streamflow exceed those in precipitation by $20 \%$. These results are consistent 
with other studies in Mediterranean climates [53], in which the streamflow is very sensitive to a decrease in precipitation in basins with high evapotranspiration rates.

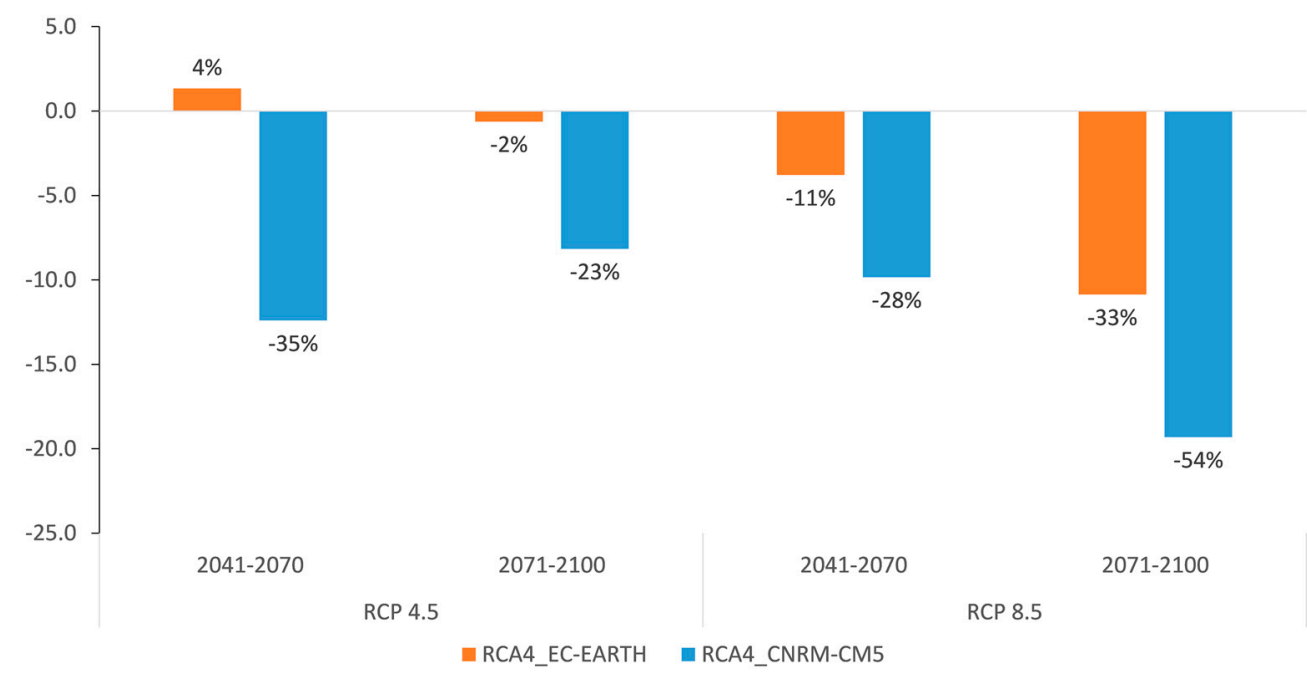

Figure 5. Annual streamflow change in the medium term (2041-2070) and the long term (2071-2100).

\subsubsection{Seasonal Streamflow Change}

Figure 6 shows the seasonal streamflow changes resulting from the estimated scenarios. Overall, a general seasonal streamflow decrease is expected for both scenarios and models. Only in winter and spring does the RCA4_EC-EARTH model estimate an increase of streamflow, which is consistent with the increment of precipitation estimated by this model. In summer, despite a lack of a clear decrease in the precipitation, an important decrease in streamflow is estimated due to the increase in the temperature, which would cause an increase in the evapotranspiration.

a)

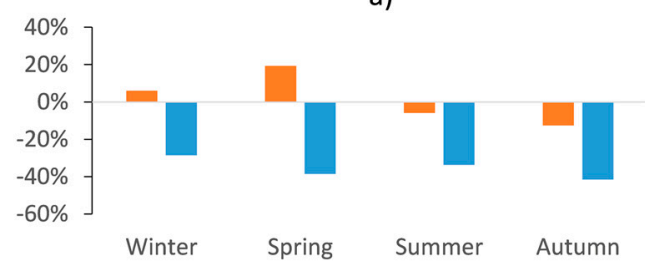

c)

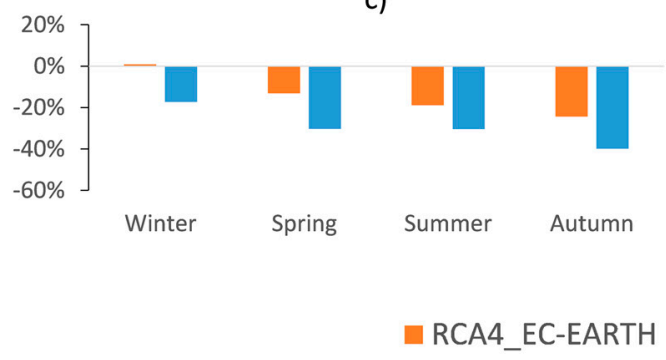

b)

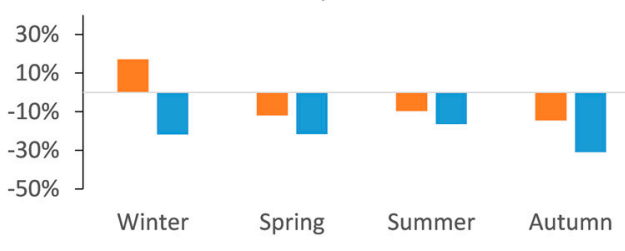

d)

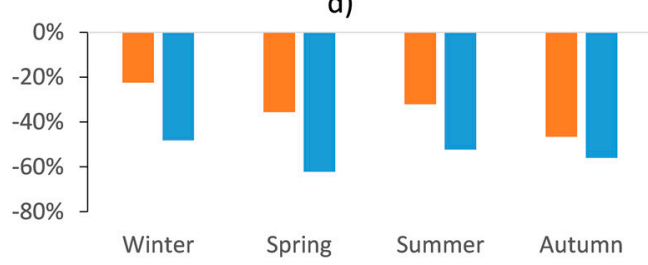

- RCA4_CNRM-CM5

Figure 6. Seasonal evolution of the mean streamflow in (a) RCP4.5 (2041-2070); (b) RCP4.5 (2071-2100); (c) RCP8.5 (2041-2070); and (d) RCP8.5 (2071-2100). 


\subsubsection{Spatial Assessment of Expected Changes}

As shown in Table 8, a significant agreement for the whole basin area was found due to the reduced extension and the homogeneous hydrological characteristics of the HWSRB. However, sub-basin 1 will suffer slightly higher reductions in its water resources.

Table 8. Spatial streamflow means distribution $\left(\mathrm{m}^{3} / \mathrm{s}\right)$ and relative changes of runoff.

\begin{tabular}{ccccccc}
\hline \multirow{2}{*}{ Subbasin } & Model & $\mathbf{1 9 7 1 - 2 0 0 0}$ & $\begin{array}{c}\text { RCP4.5 } \\
\mathbf{2 0 4 1 - 2 0 7 0}\end{array}$ & $\begin{array}{c}\text { RCP4.5 } \\
\mathbf{2 0 7 1 - 2 1 0 0}\end{array}$ & $\begin{array}{c}\mathbf{R C P 8 . 5} \\
\mathbf{2 0 4 1 - 2 0 7 0}\end{array}$ & $\begin{array}{c}\text { RCP8.5 } \\
\mathbf{2 0 7 1 - 2 1 0 0}\end{array}$ \\
\cline { 3 - 7 } & RCA4_CNRM-CM5 & 13.1 & $8.1(-38 \%)$ & $9.7(-26 \%)$ & $9.2(-30 \%)$ & $5.8(-56 \%)$ \\
\multirow{2}{*}{1} & RCA4_EC-EARTH & 12.4 & $12.7(+2 \%)$ & $12.1(-3 \%)$ & $10.7(-13 \%)$ & $8.1(-35 \%)$ \\
\hline \multirow{2}{*}{2} & RCA4_CNRM-CM5 & 16.0 & $11.0(-31 \%)$ & $12.9(-20 \%)$ & $11.9(-25 \%)$ & $7.5(-53 \%)$ \\
& RCA4_EC-EARTH & 14.6 & $15.5(+6 \%)$ & $14.5(-1 \%)$ & $13.3(-9 \%)$ & $10.1(-31 \%)$ \\
\hline \multirow{2}{*}{3} & RCA4_CNRM-CM5 & 35.5 & $23.1(-35 \%)$ & $27.3(-23 \%)$ & $25.6(-28 \%)$ & $16.2(-54 \%)$ \\
& RCA4_EC-EARTH & 33.1 & $34.4(+4 \%)$ & $32.5(-2 \%)$ & $29.3(-11 \%)$ & $22.2(-33 \%)$ \\
\hline
\end{tabular}

\section{Conclusions}

In this study the impacts of projected climate change on water resources in the HWSRB were assessed. The Soil and Water Assessment Tool was used to simulate watershed hydrological processes, and the fuzzy TOPSIS technique was applied in order to select suitable RCM-GCM combinations and reduce uncertainties associated with climate modelling. Simulations with the calibrated model were then conducted for the medium term (2041-2070) and the long term (2071-2100) under two different representative concentration pathways, RCP4.5 and RCP8.5, based on CMIP5. The main findings can be summarised as follow:

- The SWAT model was able to reproduce the current hydrological conditions of the basin. The statistical results of calibration were NSE $=0.80, \mathrm{RSR}=0.45$, and PBIAS $=1.22$. The validation results were NSE $=0.77, \mathrm{RSR}=0.48$, and PBIAS $=-12.68$. These results are indicative of the SWAT model's good performance.

- $\quad$ NRMS, CC, and SS were used to rank nine coupled runs of the GCM-RCM model, applying the fuzzy TOPSIS technique. Higher relative closeness was obtained by RCA4_CNRM-CM5 and RCA4_EC-EARTH. That is why these combinations were suggested for the assessment of the impact of climate change in the HWSRB.

- Based on the future projections, average annual temperature will increase about $3{ }^{\circ} \mathrm{C}$ and precipitation will decrease by $32 \%$ by the end of the century.

- Compared with the baseline period (1971-2000), future water resources in the HWSRB will experience a considerable change as the result of the changing temperature and precipitation. In the medium term (2041-2070), streamflow presents a high variability under the RCP4.5 and RCP8.5 scenarios, respectively. The largest alterations to streamflow are projected under RCP8.5 for 2071-2100, when they will decline between $33 \%$ and $54 \%$.

- The results obtained from this modelling study may have strong implications in a basin that is already suffering from high water stress. The simulated impacts of climate change should be incorporated into water resource management plans to develop sustainable strategies. Future strategies should be focussed on decreasing demands and increasing the amount of unconventional water resources, but if the magnitude of the climate change renders these strategies insufficient, the need for new water transfer from another basin could arise.

Acknowledgments: This research has been partially supported by the Euro-mediterranean Water Institute (Grant No. 57/15) and the Spanish MINECO (Grant No. TIN2016-78799-P). We would also like to thank the SPAIN02 and CORDEX projects for the data provided for this study. In addition, we acknowledge Papercheck Proofreading \& Editing Services. 
Author Contributions: Javier Senent-Aparicio designed the experiments and wrote the manuscript. Julio Pérez-Sánchez helped to perform the experiments and reviewed and helped to prepare this paper for publication. Jesús Carrillo-García performed the set-up, calibration, and validation of the model, as well as scenario simulations. Jesús Soto applied the fuzzy TOPSIS technique in order to select climate change models.

Conflicts of Interest: The authors declare no conflict of interest.

\section{References}

1. Arnell, N.W. Climate change and global water resources. Glob. Environ. Chang. 1999, 9, 31-49. [CrossRef]

2. Vargas-Amelin, E.; Pindado, P. The challenge of climate change in Spain: Water resources, agriculture and land. J. Hydrol. 2014, 518, 243-249. [CrossRef]

3. Estrela, T.; Pérez-Martín, M.A.; Vargas, E. Impacts of climate change on water resources in Spain. Hydrol. Sci. J. 2012, 57, 1154-1167. [CrossRef]

4. Senent-Aparicio, J.; Pérez-Sánchez, J.; Bielsa-Artero, A.M. Asessment of Sustainability in Semiarid Mediterranean Basins: Case Study of the Segura Basin, Spain. Water Technol. Sci. 2016, 7, 67-84.

5. Segura Basin Management Plan, 2015-2021. Available online: https://www.chsegura.es/chs/ planificacionydma/planificacion15-21/ (accessed on 11 December 2016).

6. Rodríguez-Estrella, T. The problems of overexploitation of aquifers in semi-arid areas: The Murcia Region and the Segura Basin (South-east Spain) case. Hydrol. Earth Syst. Sci. Discuss. 2012, 9, 5729-5756. [CrossRef]

7. García-Ruiz, J.M.; López-Moreno, J.I.; Vicente-Serrano, S.M.; Lasanta-Martínez, T.; Beguería, S. Mediterranean water resources in a global change scenario. Earth Sci. Rev. 2011, 105, 121-139. [CrossRef]

8. Gassman, P.W.; Sadeghi, A.M.; Srinivasan, R. Applications of the SWAT modle special section: Overview and insights. J. Environ. Qual. 2014, 43, 1-8. [CrossRef] [PubMed]

9. Raposo, J.R.; Dafonte, J.; Molinero, J. Assessing the impact of future climate change on groundwater recharge in Galicia-Costa, Spain. Hydrogeol. J. 2013, 21, 459-479. [CrossRef]

10. Arias, R.; Rodriguez-Blanco, M.L.; Taboada-Castro, M.M.; Nunes, J.P.; Keizer, J.J.; Taboada-Castro, M.T. Water resources response to changes in temperature, rainfall and $\mathrm{CO}_{2}$ concentration: A first approach in NW Spain. Water 2014, 6, 3049-3067. [CrossRef]

11. Moran-Tejeda, E.; Lorenzo-Lacruz, J.; López-Moreno, J.I.; Rahman, K.; Beniston, M. Streamflow timing of mountain rivers in Spain: Recent changes and future projections. J. Hydrol. 2014, 517, 1114-1127. [CrossRef]

12. Zabaleta, A.; Meaurio, M.; Ruiz, E.; Antigüedad, I. Simulation climate change impact on runoff and sediment yield in a small watershed in the Basque Country, northern Spain. J. Environ. Qual. 2013, 43, 235-245. [CrossRef] [PubMed]

13. Morán-Tejeda, E.; Zabalza, J.; Rahman, K.; Gago-Silva, A.; López-Moreno, J.I.; Vincente-Serrano, S.; Lehmann, A.; Tague, C.L.; Beniston, M. Hydrological impacts of climate and land-use changes in a mountain watershed: Uncertainty estimation based on model comparison. Ecohydrology 2015, 8, 1396-1416. [CrossRef]

14. Palazón, L.; Navas, A. Land use sediment production response under different climatic conditions in an alpine-prealpine catchment. Catena 2016, 137, 244-255. [CrossRef]

15. Pascual, D.; Pla, E.; Lopez-Bustins, J.A.; Retana, J.; Terradas, J. Impacts of climate change on water resources in the Mediterranean Basin: A case study in Catalonia, Spain. Hydrol. Sci. J. 2015, 60, 2132-2147. [CrossRef]

16. Hwang, C.L.; Yoon, K. Multiple Attribute Decision Making. Methods and Applications; Springer: Heidelberg, Germany, 1981.

17. Cavallaro, F.; Zavadskas, E.K.; Raslanas, S. Evaluation of Combined Heat and Power (CHP) Systems Using Fuzzy Shannon Entropy and Fuzzy TOPSIS. Sustainability 2016, 8, 556. [CrossRef]

18. Beskese, A.; Demir, H.H.; Ozcan, H.K.; Okten, H.E. Landfill site selection using fuzzy AHP and fuzzy TOPSIS: A case study for Istanbul. Environ. Earth Sci. 2015, 73, 3513-3521. [CrossRef]

19. Guo, S.; Zhao, H. Optimal site selection of electric vehicle charging station by using fuzzy TOPSIS based on sustainability perspective. Appl. Energy 2015, 158, 390-402. [CrossRef]

20. Raju, K.S.; Kumar, D.N. Fuzzy Approach to Rank Global Climate Models. In Proceedings of the Fifth International Conference on Fuzzy and Neuro Computing (FANCCO-2015); Ravi, V., Panigrahi, B.K., Das, S., Suganthan, P.N., Eds.; Springer International Publishing: Cham, Switzerland, 2015; pp. 53-62.

21. Won, K.; Chung, E.; Choi, S. Parametric Assessment of Water Use Vulnerability Variations Using SWAT and Fuzzy TOPSIS Coupled with Entropy. Sustainability 2015, 7, 12052-12070. [CrossRef] 
22. Jacob, D.; Petersen, J.; Eggert, B.; Alias, A.; Christensen, O.B.; Bouwer, L.M.; Braun, A.; Colette, A.; Deque, M.; Georgievski, G.; et al. EURO-CORDEX: New high-resolution climate change projections for European impact research. Reg. Environ. Chang. 2014, 14, 563-578. [CrossRef]

23. FAO. FAO/UNESCO Soil Map of the World: Revised Legend; FAO World Resources Report 60; Food and Agricultural Organization of the United Nations: Rome, Italy, 1988.

24. Arnold, J.G.; Srinavasan, R.; Muttiah, R.S.; Williams, J.R. Large-area hydrologic modeling and assessment: Part I. Model development. J. Am. Water Resour. Assoc. 1998, 34, 73-89. [CrossRef]

25. National Center for Geographic Information. Available online: http://www.cnig.es (accessed on 16 June 2016).

26. Herrera, S.; Fernández, J.; Gutiérrez, J.M. Update of the Spain02 gridded observational dataset for EURO-CORDEX evaluation: Assessing the effect of interpolation methodology. Int. J. Climatol. 2016, 36, 900-908. [CrossRef]

27. Hargreaves, G.H. Defining and using reference evapotranspiration. J. Irrig. Drain. Eng. 1994, 120, 1132-1139. [CrossRef]

28. Oudin, L.; Hervieu, F.; Michel, C.; Perrin, C.; Andréassian, V.; Anctil, F.; Loumagne, C. Which potential evapotranspiration input for a lumped rainfall-runoff model? Part 2-Towards a simple and efficient potential evapotranspiration model for rainfall-runoff modeling. J. Hydrol. 2005, 303, 290-306. [CrossRef]

29. Hydrographical Study Centre. Available online: http://ceh-flumen64.cedex.es/anuarioaforos/default.asp (accessed on 16 June 2016).

30. Corine Land Cover 2006 Seamless Vector Data-European Environment Agency. Available online: http: / / www.eea.europa.eu/data-and-maps/data/clc-2006-vector-data-version-3 (accessed on 11 June 2016).

31. Nachtergaele, F.; van Velthuizen, H.; Verelst, L.; Batjes, N.; Dijkshoorn, K.; van Engelen, V.; Fischer, G.; Jones, A.; Montanarella, L.; Petri, M. Harmonized World Soil Database; Food and Agriculture Organization of the United Nations: Rome, Italy, 2008.

32. Abbaspour, K.C. SWAT Calibration and Uncertainty Program-A User Manual; SWAT-CUP-2012; Swiss Federal Institute of Aquatic Science and Technology: Dubendorf, Switzerland, 2012.

33. Abbaspour, K.C.; Johnson, C.A.; Genuchten, M.T.V. Estimating Uncertain Flow and Transport Parameters Using a Sequential Uncertainty Fitting Procedure. Vadose Zone J. 2004, 3, 1340-1352. [CrossRef]

34. Nash, J.E.; Sutcliffe, J.V. River flow forecasting through conceptual models. Part I: A discussion of principles. J. Hydrol. 1970, 10, 282-290. [CrossRef]

35. Moriasi, D.N.; Arnold, J.G.; van Liew, M.W.; Bingner, R.L.; Harmel, R.D.; Veith, T.L. Model evaluation guidelines for systematic quantification of accuracy in watershed simulations. Trans. ASABE 2007, 50, 885-900. [CrossRef]

36. Kotlarski, S.; Keuler, K.; Christensen, O.B.; Colette, A.; Deque, M.; Gobiet, A.; Goergen, K.; Jacob, D.; Luthi, D.; van Meijgaard, E.; et al. Regional climate modelling on European scales: A joint standard evaluation of the EURO-CORDEX RCM ensemble. Geosci. Model Dev. 2014, 7, 1297-1333. [CrossRef]

37. Van Vuuren, D.P.; Edmonds, J.; Kainuma, M.; Riahi, K.; Thomson, A.; Hibbard, K.; Hurtt, G.C.; Kram, T.; Krey, V.; Lamarque, J.F. The representative concentration pathways: An overview. Clim. Chang. 2011, 109, 5-31. [CrossRef]

38. Chen, J.; Brissette, F.; Lucas-Picher, P. Transferability of optimally-selected climate models in the quantification of climate change impacts on hydrology. Clim. Dyn. 2016, 47, 3359-3372. [CrossRef]

39. Teutschbein, C.; Seibert, J. Bias corretion of regional climate model simulations for hydrological climate-change impact studies: Review and evaluation of different methods. J. Hydrol. 2012, 456-457, 12-29. [CrossRef]

40. Rathjens, H.; Bieger, K.; Srinivasan, R.; Chaubey, I.; Arnold, J.G. CMhyd User Manual. Available online: http://swat.tamu.edu/software/cmhyd/ (accessed on 23 September 2016).

41. Perkins, S.E.; Pitman, A.J.; Holbrook, N.J.; McAveney, J. Evaluation of the AR4 climate models simulated daily maximum temperature, minimum temperature and precipitation over Australia using probability density functions. J. Clim. 2007, 20, 4356-4376. [CrossRef]

42. Conan, C.; de Marsily, G.; Bouraoui, F.; Bidoglio, G. A long-term hydrological modeling of the upper Guadiana river basin (Spain). Phys. Chem. Earth 2003, 28, 193-200. [CrossRef] 
43. Galván, L.; Olías, M.; de Villarán, R.F.; Santos, J.M.D.; Nieto, J.M.; Sarmiento, A.M.; Cánovas, C.R. Application of the SWAT model to an AMD-affected river (Meca River, SW Spain). Estimation of transported pollutant load. J. Hydrol. 2009, 377, 445-454. [CrossRef]

44. Molina-Navarro, E.; Martínez-Pérez, S.; Sastre-Merlín, A.; Bienes-Allas, R. Hydrologic modeling in a small mediterranean basin as a tool to assess the feasibility of a limno-reservoir. J. Environ. Qual. 2014, 43, 121-131. [CrossRef] [PubMed]

45. Bressiani, D.D.A.; Srinivasan, R.; Jones, C.A.; Mendiondo, E.M. Effects of spatial and temporal weather data resolutions on streamflow modeling of a semi-arid basin, northeast Brazil. Int. J. Agric. Biol. Eng. 2015, 8, 14-25.

46. Neitsch, S.L.; Arnold, J.G.; Kiniry, J.T.; Williams, J.R. Soil and Water Assessment Tool. Theoretical Documentation Version 2009. Available online: http://swat.tamu.edu/media/99192/swat2009-theory.pdf (accessed on 3 June 2016).

47. Begou, J.C.; Jomaa, S.; Benabdallah, S.; Bazie, P.; Afouda, A.; Rode, M. Multi-Site Validation of the SWAT Model on the Bani Catchment: Model Performance and Predictive Uncertainty. Water 2016, 8, 178. [CrossRef]

48. Martínez-Casasnovas, J.A.; Ramos, M.C.; Benites, G. Soil and Water Assessment Tool Soil Loss Simulation at the Sub-Basin Scale in the Alt Penedès-Anoia Vineyard Region (Ne Spain) in the 2000s. Land Degrad. Dev. 2016, 27, 160-170. [CrossRef]

49. AEMET 2017. Climate Projections for the XXI Century. Available online: http://www.aemet.es/es/ serviciosclimaticos/cambio_climat/ (accessed on 31 January 2017).

50. Sellami, H.; Benabdallah, S.; La Jeunesse, I.; Vanclooster, M. Quantifying hydrological responses of small Mediterranean catchments under climate change projections. Sci. Total Environ. 2016, 543, 924-936. [CrossRef] [PubMed]

51. Centre for Public Works Studies and Experimentation (CEDEX). Evaluación del Impacto del Cambio Climático en los Recursos Hídricos en Régimen Natural (In Spanish). 2017. Available online: http://www.mapama.gob.es/es/cambio-climatico/publicaciones/publicaciones/Memoria_ encomienda_CEDEX_tcm7-165767.pdf (accessed on 31 January 2017).

52. Li, F.; Zhang, G.; Xu, Y.J. Assessing climate change impacts on water resources in the Songhua River basin. Water 2016, 8, 420. [CrossRef]

53. Molina-Navarro, E.; Hallack-Alegría, M.; Martínez-Pérez, S.; Ramírez-Hernández, J.; Mungaray-Moctezuma, A.; Sastre-Merlín, A. Hydrological modeling and climate change impacts in an agricultural semiarid region. Case study: Guadalupe River basin, Mexico. Agric. Water Manag. 2016, 175, 29-42. [CrossRef] 